\title{
Impact of selected risk factors on uterine healing after cesarean section in women with single-layer uterine closure: A prospective study using two- and three-dimensional transvaginal ultrasonography
}

\author{
Joanna Budny-Wińska ${ }^{A-D}$, Aleksandra Zimmer-Stelmach ${ }^{B, C}$, Michał Pomorski ${ }^{D-F}$ \\ $2^{\text {nd }}$ Department of Gynecology and Obstetrics, Wroclaw Medical University, Poland \\ A - research concept and design; $\mathrm{B}$ - collection and/or assembly of data; $\mathrm{C}$ - data analysis and interpretation; \\ $D$ - writing the article; $E$ - critical revision of the article; $F$ - final approval of the article
}

Address for correspondence

Joanna Budny-Wińska

E-mail: joanna.budny-winska@umed.wroc.pl

Funding sources

None declared

Conflict of interest

None declared

Received on June 20, 2021

Reviewed on August 11, 2021

Accepted on September 22, 2021

Published online on November 4, 2021

Cite as

Budny-Wińska J, Zimmer-Stelmach A, Pomorski M. Impact of selected risk factors on uterine healing after cesarean section in women with single-layer uterine closure: A prospective study using two- and three-dimensional transvaginal ultrasonography. Adv Clin Exp Med. 2022;31(1):41-48. doi:10.17219/acem/142519

DOI

10.17219/acem/142519

Copyright

Copyright by Author(s)

This is an article distributed under the terms of the

Creative Commons Attribution 3.0 Unported (CC BY 3.0)

(https://creativecommons.org/licenses/by/3.0/)

\begin{abstract}
Background. Modern obstetrics must meet many challenges, including long-term complications resulting from the presence of a uterine niche after cesarean section.

Objectives. To assess the impact of selected risk factors on the uterine healing process after cesarean section. The uterus was closed with a single-layer continuous suture covering the entire thickness of the myometrium, excluding the decidua.
\end{abstract}

Materials and methods. A prospective, case-controlled study was carried out at $2^{\text {nd }}$ Department of Gynecology and Obstetrics, Wroclaw Medical University, Poland. Women who delivered by cesarean section at our Department were invited to undergo an ultrasonographic assessment of the cesarean section scar from 6 to 9 weeks after the procedure. In all cases, the uterus was closed with a single-layer continuous suture. The ultrasound examination of the niche was performed according to the modified Delphi protocol. The volume of the niche was calculated and a 3D model was created. The obtained data were analyzed with clinical information from the maternal medical history and the course of the pregnancy.

Results. A total of 204 patients participated in the study. Five patients had a residual myometrial thickness (RMT) $<2.2 \mathrm{~mm}$ and 35 had a residual myometrial thickness to adjacent myometrial thickness ratio (RMT/AMT) $\leq 0.5$. In 45\% of women, pregnancy course was complicated by gestational diabetes mellitus (GDM), gestational hypertension and hypothyroidism. The cervical canal was colonized with pathogenic flora in 22\% of women. No correlation between maternal and gestational age at delivery, presence of medical complications during pregnancy, colonization of the cervical canal, and presence of niche and its parameters were found.

Conclusions. Our study revealed that the selected risk factors, such as systemic diseases during pregnancy and in the maternal medical history, as well as the colonization of the cervical canal, have no impact on uterine scar healing in women undergoing single-layer uterine closure spanning the entire thickness of the myometrium, excluding the decidua.

Key words: 3D ultrasonography, cesarean scar niche, risk factors of cesarean scar niche, systemic diseases during pregnancy, single-layer suture 


\section{Background}

Modern obstetrics must meet many challenges, including the increased frequency of cesarean sections and long-term complications resulting from the presence of a uterine niche after cesarean section. Additionally, worldwide, there has been an increased incidence and prevalence of systemic diseases appearing in pregnancy, such as gestational hypertension and gestational diabetes mellitus (GDM). ${ }^{1,2}$ The another challenge for obstetricians is the increased rate of pregnancy among older women ${ }^{3,4}$ due to the sociocultural changes in family planning that leads to the postponement of maternal plans, as well as the improved availability and effectiveness of assisted reproductive methods.

The consequence of cesarean section is a scar formation within the uterine muscle. In recent years, the rate of deliveries by cesarean section has increased all over the world. In Poland, the rate of cesarean section is $44.8 \%$ (data from Statistics Poland for 2019). The World Health Organization (WHO) recommends an ideal cesarean section rate of $10-15 \%$ of all births. This percentage is associated with a decrease in maternal and neonatal mortality. Above this level, the increased incidence of cesarean delivery is no longer associated with reduced mortality. ${ }^{5}$

With rising cesarean rates, the incidence of cesarean-related iatrogenic complications is also on the rise. In cases of incomplete healing, a niche can develop within the scar.

Various imaging methods including two- and threedimensional ultrasonography, sonohysterography, hysterography, hysteroscopy, and magnetic resonance imaging (MRI) can be used to assess the anterior uterine wall and to diagnose a cesarean scar niche. ${ }^{6-8}$ Despite the availability of various diagnostic methods, there are no clear diagnostic criteria for uterine niches after cesarean section. In 2019, the European Niche Taskforce defined a uterine niche as an indentation of at least $2 \mathrm{~mm}$ in the uterine myometrium at the site of the cesarean scar, assessed using transvaginal ultrasound. ${ }^{9}$ The incidence of uterine niches varies widely in the literature, ranging from $24 \%$ to $84 \% .{ }^{10-13}$

Differences in the frequency of uterine niches result from the use of different diagnostic criteria, the time elapsed after the cesarean procedure and the diagnostic method used. The incidence is often underestimated because many women are asymptomatic and clinicians may not consider a niche as a cause of a patient's symptoms, due to lack of awareness. ${ }^{8}$

Most of the small uterine niches after cesarean section are asymptomatic and do not pose a threat to the health or life of the patient. However, the consequences of the presence of the large and symptomatic cesarean scar niche include uterine bleeding, chronic pelvic pain, reduced fertility, complications in subsequent pregnancies (morbidly adherent placenta, placenta previa), as well as directly life-threatening conditions (uterine rupture, cesarean scar pregnancy). ${ }^{6,14-17}$ Additionally, cesarean scar niches may increase the risk of complications in gynecological procedures such as embryo transfer and intrauterine device placement and removal. ${ }^{18,19}$

Due to the potentially dangerous consequences resulting from the presence of a uterine niche after cesarean section, it is necessary to develop preventive strategies aimed at reducing the risk of isthmocele formation, and thus preventing adverse outcomes. To achieve this, it is essential to identify related risk factors for the formation of a uterine niche after cesarean section, and to develop appropriate diagnostic and therapeutic protocols. Therefore, in the past several years, numerous studies have been published concerning the uterine scar niche, but most of them have been performed using selected populations of symptomatic women.

\section{Objectives}

This study aimed to assess the impact of the most common risk factors in obstetrics on the uterine healing process after cesarean section, using a prospectively collected and unselected population, in which the uterus was closed with a single-layer continuous suture covering the entire thickness of the myometrium, excluding the decidua.

\section{Materials and methods}

\section{Study design}

This prospective descriptive study was designed to assess the prevalence and risk factors for improper uterine healing after cesarean delivery and niche formation. This study is a continuation of our previous research, in which we assessed the impact of mode and number of previous cesarean sections, type of uterine incision expansion, operator's experience, uterine flexion, and stage of labor at the time of cesarean section on uterine healing. ${ }^{20}$

\section{Setting and participants}

The study was carried out at $2^{\text {nd }}$ Department of Gynecology and Obstetrics, Wroclaw Medical University, Poland. The study protocol was accepted by the ethics committee (approval No. KB 221/2016 and No. KB 153/2020) and all participants signed an informed consent form before participating in the study. The study was conducted in accordance with the 1964 Declaration of Helsinki and its later amendments.

Women who delivered by cesarean section at our Department from 2017 to 2019 were invited to undergo an ultrasonographic assessment of the cesarean section 
scar. They were recruited either before the cesarean delivery (elective surgery) or within 2 days after the operation (emergency cesarean delivery). Patients who agreed to participate in the study were scheduled for the ultrasound examination from 6 to 9 weeks after the cesarean section.

\section{Surgical technique}

The cesarean section procedures were performed by various obstetricians working in our Department using a standardized manner, i.e., low transverse uterine incision with a single-layer continuous suture covering the entire thickness of the myometrium, excluding the decidua. All physicians used the same suture material (Surgicryl ${ }^{\circledR} 910$ polyglactine-braided synthetic absorbable suture; SMI AG, St. Vith, Belgium).

\section{Ultrasound examination}

The examinations were conducted using a Voluson V8 Expert ultrasound machine (General Electric Medical Systems, Chicago, USA) with a 4-9 MHz transvaginal $3 \mathrm{D}$ probe. All transvaginal ultrasound examinations were performed by the first author, who was blinded to clinical information. During the examination, the parameters of the niche were assessed and a 3D model was created. All data were saved on the internal hard drive of the ultrasound machine. According to the international definition, a niche was defined as an indentation in the myometrium of at least $2 \mathrm{~mm} .{ }^{9}$ All measurements were obtained on a sagittal view of the uterus. To standardize the ultrasound evaluation, all examinations were performed using the modified Delphi protocol, and the exams performed prior to the publication of the modified Delphi protocol were reloaded and recalculated in accordance with the guidelines. ${ }^{9}$

The following niche parameters were assessed according to the modified Delphi protocol: width (W [mm]), height (D [mm]), volume of the anechoic triangle, residual myometrial thickness (RMT [mm]), and adjacent myometrial thickness (AMT [mm]). Additionally, the following parameters were calculated: the RMT/AMT ratio, the RMT/W ratio and the $\mathrm{RMT} / \mathrm{D}$ ratio.

The VOCAL program was used to create $3 \mathrm{D}$ models and calculate the volume of the niche. The following settings were used: manual trace and rotation angle of $15^{\circ}$. The boundaries of the anechoic niche were manually outlined on the touch screen of the Voluson V8 Expert ultrasound machine.

\section{Clinical data analysis}

Clinical information, such as laboratory results, maternal medical history pregnancy, and cesarean section course, was collected from the medical record and analyzed after ultrasonographic assessment of the cesarean section scar.

\section{Inclusion and exclusion criteria}

The inclusion criteria were low transverse uterine incision, single-layer continuous full thickness uterine closure, uneventful postoperative course and singleton pregnancy. The exclusion criteria included a vertical or inverted " $\mathrm{T}$ " uterine incision, congenital uterine malformations and the use of more than 3 additional hemostatic uterine sutures.

\section{Statistical analyses}

Data were collected and recorded using an Excel spreadsheet. Statistical analyses were performed using the STATISTICA v. 13.3 PL package (StatSoft Inc., Tulsa, USA). For quantitative variables, basic descriptive statistics were calculated (for all patients and taking into account the assumed division into groups), while the frequency of occurrence of their individual variants was calculated for qualitative variables (also taking into account the assumed division). The Mann-Whitney $U$ test, post hoc comparisons for the Kruskal-Wallis analysis of variance (ANOVA) test and non-parametric Spearman's rank correlation test were used in the analysis of non-parametric data. The Pearson's $X^{2}$ test and Fisher's exact test were used to evaluate the differences in the distributions of qualitative variables. The criterion for statistical significance was set at a p-value $<0.05$.

\section{Results}

A total of 204 patients participated in the study. The mean age was 32.25 years (standard deviation (SD) \pm 4.156$)$ and the mean gestational age was 37.863 weeks $(\mathrm{SD} \pm 2.43)$. A total of 117 (57\%) participants had no previous deliveries. Of the 204 patients, $56(27 \%)$ had at least 1 cesarean section in the past, while $32(16 \%)$ had at least 1 previous vaginal delivery. Eighty-two (40\%) patients underwent emergency cesarean delivery and 122 (60\%) underwent elective cesarean delivery. The most common reasons for elective cesarean delivery were previous cesarean delivery (40\%) and breech presentation (9\%). The most common reasons for emergency cesarean delivery were impending fetal asphyxia (40\%) and prolonged labor (17\%).

Out of all examined women, 153 were diagnosed with a niche after cesarean section (75\%). Five of those patients had a RMT $<2.2 \mathrm{~mm}$ and 35 patients had an RMT/AMT ratio of 0.5 or less. The mean RMT value in the study group was $8.3 \mathrm{~mm}(\mathrm{SD} \pm 3.37$ ).

The course of pregnancy was uncomplicated by pregnancy-related systemic diseases in 55\% ( $n=112)$ of women. In this group, uterine scar niches were diagnosed after cesarean section in $71 \%(n=79)$ of patients. In contrast, in 21 patients $(10 \%)$ with GDM, a uterine niche was diagnosed after cesarean section in 91\% of these women. In $11 \%$ of respondents, their pregnancy was complicated 
Table 1. Comparison of the analyzed variables and the occurrence of uterine niche after the cesarean section

\begin{tabular}{|c|c|c|c|c|c|c|c|c|}
\hline \multirow{2}{*}{ Variable } & \multicolumn{2}{|c|}{$\begin{array}{l}\text { Chronic diseases } \\
\text { in pregnancy }\end{array}$} & \multicolumn{2}{|c|}{ Gestational diabetes } & \multicolumn{2}{|c|}{ Gestational hypertension } & \multicolumn{2}{|c|}{ Culture of cervical canal } \\
\hline & yes & no & yes & no & yes & no & negative & positive \\
\hline Niche, n (\%) & $75(49)$ & $78(51)$ & $18(12)$ & $135(88)$ & $14(9)$ & $139(91)$ & $92(79)$ & $24(21)$ \\
\hline Non-niche, n (\%) & $17(33)$ & $34(67)$ & $3(6)$ & 48 (94) & $9(18)$ & $42(82)$ & $32(76)$ & $10(24)$ \\
\hline$p$-value* & \multicolumn{2}{|c|}{0.0536} & \multicolumn{2}{|c|}{0.2949} & \multicolumn{2}{|c|}{0.1236} & \multicolumn{2}{|c|}{0.6665} \\
\hline
\end{tabular}

*Fisher's exact test.

Table 2. Characteristics of the parameters of the cesarean scar niche depending on the occurrence of systemic diseases during pregnancy and cervical colonization (Mann-Whitney U test)

\begin{tabular}{|c|c|c|c|c|c|c|c|c|c|c|}
\hline \multirow[t]{2}{*}{ Variable } & \multicolumn{2}{|c|}{$\begin{array}{c}\text { Chronic diseases } \\
\text { in pregnancy }\end{array}$} & \multicolumn{2}{|c|}{ Gestational diabetes } & \multicolumn{2}{|c|}{$\begin{array}{c}\text { Gestational } \\
\text { hypertension }\end{array}$} & \multicolumn{2}{|c|}{$\begin{array}{l}\text { Hypothyroidism } \\
\text { in pregnancy }\end{array}$} & \multicolumn{2}{|c|}{$\begin{array}{c}\text { Culture } \\
\text { of cervical canal } \\
\end{array}$} \\
\hline & yes & no & yes & no & yes & no & yes & no & positive & negative \\
\hline \multicolumn{11}{|c|}{ Height [cm] } \\
\hline Mean (SD) & $0.50(0.24)$ & $0.49(0.20)$ & $0.54(0.24)$ & $0.49(0.22)$ & $0.51(0.33)$ & $0.49(0.21)$ & $0.49(0.21)$ & $0.51(0.23)$ & $0.49(0.18)$ & $0.52(0.23)$ \\
\hline p-value & \multicolumn{2}{|c|}{0.7150} & \multicolumn{2}{|c|}{0.5091} & \multicolumn{2}{|c|}{0.5491} & \multicolumn{2}{|c|}{0.7047} & \multicolumn{2}{|c|}{0.5346} \\
\hline \multicolumn{11}{|c|}{ Width [cm] } \\
\hline Mean (SD) & $0.80(0.36)$ & $0.83(0.37)$ & $0.80(0.33)$ & $0.82(0.37)$ & $0.79(0.43)$ & $0.82(0.35)$ & $0.80(0.34)$ & $0.83(0.37)$ & $0.76(0.24)$ & $0.84(0.40)$ \\
\hline p-value & \multicolumn{2}{|c|}{0.4332} & \multicolumn{2}{|c|}{0.9848} & \multicolumn{2}{|c|}{0.4332} & \multicolumn{2}{|c|}{0.6807} & \multicolumn{2}{|c|}{0.5435} \\
\hline \multicolumn{11}{|c|}{ Residual myometrial thickness $[\mathrm{cm}]$} \\
\hline Mean (SD) & $0.84(0.35)$ & $0.82(0.33)$ & $0.84(0.30)$ & $0.83(0.34)$ & $0.87(0.32)$ & $0.82(0.34)$ & $0.82(0.35)$ & $0.83(0.33)$ & $0.81(0.29)$ & $0.82(0.35)$ \\
\hline$p$-value & \multicolumn{2}{|c|}{0.3905} & \multicolumn{2}{|c|}{0.9487} & \multicolumn{2}{|c|}{0.3905} & \multicolumn{2}{|c|}{0.8058} & \multicolumn{2}{|c|}{0.8590} \\
\hline \multicolumn{11}{|c|}{ Adjacent myometrial thickness [cm] } \\
\hline Mean (SD) & $1.25(0.38)$ & $1.17(0.38)$ & $1.32(0.41)$ & $1.19(0.38)$ & $1.21(0.32)$ & $1.21(0.39)$ & $1.23(0.38)$ & $1.20(0.39)$ & $1.16(0.28)$ & $1.22(0.41)$ \\
\hline p-value & \multicolumn{2}{|c|}{0.6636} & \multicolumn{2}{|c|}{0.4952} & \multicolumn{2}{|c|}{0.9373} & \multicolumn{2}{|c|}{0.6962} & \multicolumn{2}{|c|}{0.7239} \\
\hline \multicolumn{11}{|c|}{ Residual myometrial thickness/adjacent myometrial thickness } \\
\hline Mean (SD) & $0.67(0.21)$ & $0.71(0.22)$ & $0.64(0.16)$ & $0.70(0.22)$ & $0.74(0.24)$ & $0.69(0.21)$ & $0.66(0.21)$ & $0.71(0.22)$ & $0.71(0.22)$ & $0.68(0.23)$ \\
\hline$p$-value & 0.7 & 392 & & & & 72 & & & & 340 \\
\hline & & & Resi & ual myomet & ial thickness & width & & & & \\
\hline Mean (SD) & $1.24(0.88)$ & $1.05(0.57)$ & $1.18(0.62)$ & $1.14(0.76)$ & $1.24(0.73)$ & $1.14(0.74)$ & $1.18(0.76)$ & $1.13(0.73)$ & $1.04(0.49)$ & $1.16(0.81)$ \\
\hline$p$-value & 0.4 & & & & & 332 & & & & 950 \\
\hline & & & Resic & lal myometr & al thickness & neight & & & & \\
\hline Mean (SD) & $1.96(1.40)$ & $1.81(1.19)$ & $1.76(0.90)$ & $1.89(1.34)$ & $1.98(1.15)$ & $1.87(1.31)$ & $1.94(1.49)$ & $1.86(1.20)$ & $1.65(0.74)$ & $1.82(1.30)$ \\
\hline$p$-value & 0.5 & 153 & & & & 53 & & 63 & & 740 \\
\hline & & & & Niche vo & ume $\left[\mathrm{cm}^{3}\right]$ & & & & & \\
\hline Mean (SD) & $0.15(0.20)$ & $0.15(0.25)$ & $0.12(0.10)$ & $0.15(0.24)$ & $0.18(0.28)$ & $0.14(0.22)$ & $0.14(0.20)$ & $0.15(0.24)$ & $0.09(0.14)$ & $0.17(0.27)$ \\
\hline$p$-value & 0.9 & 350 & & & & & & & & 362 \\
\hline
\end{tabular}

SD - standard deviation.

by gestational hypertension $(n=28)$, and among them, $65 \%$ were diagnosed with a niche of the uterus after cesarean section. Out of the 59 (29\%) patients who developed hypothyroidism during their pregnancy, $85 \%$ were diagnosed with a uterine niche after cesarean section. There was no statistical correlation between the prevalence or parameters of a uterine niche after cesarean section and the abovementioned medical complications of pregnancy.

In our study, there were no cases of postoperative, symptomatic infections. However, the influence of cervical canal colonization by microbes on the healing of uterine scars was evaluated. Swabs from the cervical canal were taken from 158 pregnant women on admission to the hospital. In $78 \%(\mathrm{n}=124)$ of pregnant women, a negative culture was reported. In $22 \%(n=34)$ of women, the culture was positive for pathogenic flora such as Staphylococcus agalactiae spp ( $\mathrm{n}=8,24 \%)$, Candida (including C. albicans spp, C. glabrata spp; $\mathrm{n}=10.29 \%$ ), Enterococcus (including E. faecalis spp; $\mathrm{n}=4.12 \%)$, Escherichia coli $\mathrm{spp}(\mathrm{n}=6.18 \%)$, Klebsiella pneumoniae spp ( $\mathrm{n}=4.12 \%)$, and Pseudomonas putida spp ( $\mathrm{n}=1.3 \%)$. The percentage of identified niches in women with negative culture was $74 \%(n=92)$. The same percentage of niches was found in the group of women with positive cultures from the cervical canal 
Table 3. Comparison of the maternal age and the occurrence of uterine niche after cesarean section

\begin{tabular}{|l|c|c|c|c|}
\multicolumn{1}{|c|}{ Variable } & $\leq 25$ years & $25-30$ years & $31-35$ years & $36-40$ years \\
\hline Niche, $n(\%)$ & $8(5)$ & $45(29)$ & $73(48)$ & $21(14)$ \\
\hline Non-niche, $n(\%)$ & $4(8)$ & $13(25)$ & $23(45)$ & $10(20)$ \\
\hline$p$-value & & & $0.7346^{*}$ & $1(2)$ \\
\hline
\end{tabular}

*Pearson's $x^{2}$ test, degrees of freedom $(\mathrm{df})=4$.

Table 4. Comparison of the parameters of the cesarean scar niche depending on maternal age

\begin{tabular}{|l|c|c|c|c|c|c|}
\multicolumn{1}{|c|}{ Variable } & $\leq 25$ years & $25-30$ years & $31-35$ years & $36-40$ years & $>40$ years & $p$-value* \\
\hline $\mathrm{H}[\mathrm{cm}]$, mean (SD) & $0.49(0.29)$ & $0.47(0.19)$ & $0.50(0.22)$ & $0.52(0.27)$ & $0.47(0.23)$ & 0.8210 \\
\hline W [cm], mean (SD) & $0.84(0.21)$ & $0.83(0.42)$ & $0.83(0.37)$ & $0.73(0.24)$ & $0.84(0.22)$ & 0.6992 \\
\hline RMT [cm], mean (SD) & $0.9(0.33)$ & $0.87(0.35)$ & $0.81(0.34)$ & $0.80(0.33)$ & $0.80(0.31)$ & 0.6749 \\
\hline AMT [cm], mean (SD) & $1.30(0.40)$ & $1.24(0.39)$ & $1.20(0.38)$ & $1.15(0.41)$ & $1.21(0.45)$ & 0.8959 \\
\hline RMT/AMT & $0.72(0.25)$ & $0.70(0.21)$ & $0.68(0.22)$ & $0.71(0.23)$ & $0.68(0.17)$ & 0.8408 \\
\hline RMT/W & $0.92(0.40)$ & $1.21(0.69)$ & $1.13(0.80)$ & $1.17(0.79)$ & $1.02(0.57)$ & 0.7671 \\
\hline RMT/H & $1.61(0.86)$ & $2.06(1.31)$ & $1.83(1.31)$ & $1.81(1.47)$ & $1.90(1.00)$ & 0.5102 \\
\hline $\begin{array}{l}\text { Niche volume }\left[\mathrm{cm}^{3}\right], \\
\text { mean (SD) }\end{array}$ & $0.20(0.21)$ & $0.16(0.30)$ & $0.14(0.20)$ & $0.12(0.11)$ & $0.16(0.25)$ & 0.8994 \\
\hline
\end{tabular}

$\mathrm{H}$ - height; W - width; RMT - residual myometrial thickness; AMT - adjacent myometrial thickness; SD - standard deviation; *Kruskal-Wallis analysis of variance (ANOVA) test.

Table 5. Comparison of the occurrence of uterine scar niche by gestational age and history of miscarriages

\begin{tabular}{|c|c|c|c|c|}
\hline \multirow{2}{*}{ Variable } & \multicolumn{2}{|c|}{ Preterm delivery } & \multicolumn{2}{|c|}{ Miscarriage in the past } \\
\hline & yes & no & yes & no \\
\hline Niche, n (\%) & $11(22)$ & $40(78)$ & $10(20)$ & $41(80)$ \\
\hline Non-niche, n (\%) & $22(14)$ & $131(86)$ & $33(22)$ & $120(78)$ \\
\hline p-value* & \multicolumn{2}{|c|}{0.2720} & \multicolumn{2}{|c|}{0.8448} \\
\hline
\end{tabular}

*Fisher's exact test.

( $\mathrm{n}=25,74 \%)$. In this study, no statistically significant correlation was found between the prevalence and parameters of the uterine scar niche and the colonization of the cervix by pathogens. Table 1 and Table 2 present the comparison data between the incidence and parameters of cesarean scar niche and systemic diseases appearing in pregnancy, and the colonization of the cervix by pathogenic bacteria.

The study group was divided into subgroups by age. Table 3 presents the detailed characteristics of each subgroup.

Also, the impact of gestational age at the time of cesarean section was assessed. In $16 \%$ of patients $(n=33)$, cesarean section was performed on a preterm pregnancy in which $67 \%(n=22)$ of these resulted in a uterine niche. In women undergoing cesarean section at term $(n=171$, $84 \%$ of patients), the percentage of uterine scar niches after cesarean section was $77 \%(n=132)$. For women with a history of miscarriages ( $n=43,21 \%$ of patients), a niche was diagnosed in $33(77 \%)$ of these patients. There was no statistical correlation between the prevalence or parameters of the niche after cesarean section and maternal age during cesarean section, preterm delivery and history of miscarriages (Table 4,5,6).

\section{Discussion}

Currently, there are no guidelines concerning the optimal timing for cesarean section scar assessment.

Most of the research concerning uterine niches after cesarean section have focused on examining women with symptoms related to its presence. The interval between cesarean section and evaluation of the cesarean scar varied in different publications. Most publications assessed the uterine scar from 6 to 8 weeks, 6 months, ${ }^{21} 1$ year, ${ }^{22}$ or more than 5 years ${ }^{23,24}$ after performing the cesarean section. This study aimed to evaluate the influence of individual factors and systemic diseases appearing during pregnancy on the process of uterine healing after cesarean section. In this study, every woman who had cesarean section with a single-layer, full thickness uterine closure excluding the decidua, was invited for a uterine scar examination. The examination was performed from 6 to 9 weeks after the operation, during which the uterine scar was still healing and no clinical symptoms are present. Van der Voet et al. found that the prevalence of niches did not change with time (niches found during an examination at 6-12 weeks after the cesarean section were also 
Table 6. Comparison of analyzed parameters of cesarean scar niche depending on the history of miscarriages and gestational age

\begin{tabular}{|l|c|c|c|c|c|c|c|}
\multirow{2}{*}{\multicolumn{1}{c|}{ Variable }} & \multicolumn{3}{|c}{ History of miscarriages } & \multicolumn{3}{c|}{ Gestational age } \\
\cline { 2 - 8 } & no & yes & $p$-value* & preterm delivery & term delivery & $p$-value* \\
\hline H [cm], mean (SD) & $0.50(0.23)$ & $0.50(0.18)$ & 0.4301 & $0.48(0.24)$ & $0.52(0.22)$ & 0.3757 \\
\hline W [cm], mean (SD) & $0.80(0.32)$ & $0.90(0.48)$ & 0.3868 & $0.81(0.48)$ & $0.82(0.34)$ & 0.3081 \\
\hline RMT [cm], mean (SD) & $0.84(0.34)$ & $0.79(0.34)$ & 0.2912 & $0.89(0.36)$ & $0.82(0.33)$ & 0.2423 \\
\hline AMT [cm], mean (SD) & $1.22(0.39)$ & $1.17(0.35)$ & 0.5697 & $1.23(0.41)$ & $1.21(0.38)$ & 0.8455 \\
\hline RMT/AMT & $0.70(0.21)$ & $0.67(0.87)$ & 0.3472 & $0.73(0.22)$ & $0.69(0.21)$ & 0.3672 \\
\hline RMT/W & $1.15(0.65)$ & $1.12(1.01)$ & 0.2202 & $1.16(0.61)$ & $1.14(0.76)$ & 0.5342 \\
\hline RMT/H & $1.91(1.27)$ & $1.77(1.40)$ & 0.1832 & $2.03(1.41)$ & $1.86(1.28)$ & 0.7800 \\
\hline Niche volume $\left[\mathrm{cm}^{3}\right]$, mean (SD) & $0.13(0.17)$ & $0.20(0.37)$ & 0.9947 & $0.23(0.43)$ & $0.13(0.17)$ & 0.9588 \\
\hline
\end{tabular}

$\mathrm{H}$ - height; W - width; RMT - residual myometrial thickness; AMT - adjacent myometrial thickness; SD - standard deviation; *Mann-Whitney U test.

present on an examination performed 1 year after cesarean section). ${ }^{25}$

Transvaginal ultrasound examination at 6-9 weeks after cesarean section allows for the identification of patients with a potential risk of abnormal uterine healing after cesarean section, due to a large niche that may threaten the next pregnancy or be the cause of cesarean scar syndrome. Patients with a large niche and low RMT, as well as physicians treating them need to be aware of the risk of possible complications as soon as possible. Currently, in our clinical practice, we found many women with abnormal uterine bleeding related to the niche, who are unnecessarily treated by other doctors with oral contraceptives or invasive procedures such as dilatation and curettage. Moreover, women with extremely low RMT face life-threatening complications in subsequent pregnancies due to the risk of scar rupture at 21 weeks of gestation. ${ }^{26}$ Taking into consideration the above problems and the limited knowledge gynecologists have of niche-related complications, we suggest cesarean section scar assessment be routinely performed in all women who have undergone cesarean section at the end of puerperium.

In this study, all niches, whether classified as small or large, were assessed using two and three-dimensional ultrasound. ${ }^{7}$ Even though 2 meta-analyses have concluded single-layer closure to be associated with decreased RMT in comparison to double-layer sutures, in our study group, only $2.4 \%$ of women had a RMT $<2.2 \mathrm{~mm}$. An RMT $<2.2 \mathrm{~mm}$ is considered a risk factor for severe scar complications in subsequent pregnancies. ${ }^{9}$ Both of these meta-analyses have shown no differences in the risk of maternal morbidity or long-term outcomes between singlecompared to double-layer uterine closure. ${ }^{27,28}$

This study is a continuation of our previous research in which we proved there was no correlation between an operator's experience and the prevalence and parameters of uterine niches after cesarean section. ${ }^{20}$ The lack of a relationship between the operator's experience and the formation of a uterine niche after cesarean section is supported in the literature. ${ }^{11}$ It should be emphasized that all cesarean sections were performed in a standardized manner, i.e., low transverse uterine incision with single-layer full thickness uterine closure using the same suture material.

There was also no correlation between the parameters of the niche, incidence of niches and a woman's age at the time of cesarean section, which is in line with other studies. ${ }^{29}$ In the study by Pomorski et al., a positive correlation was found between the height of the niche and the mother's age. ${ }^{30}$ In another publication, the presence of a niche was significantly associated with younger maternal age at the time of cesarean section. In this study, younger patients had cesarean section performed during the active phase of labor. ${ }^{31}$ According to some studies, performing cesarean section during the active phase of labor or phase II of labor increases the risk of a large niche formation. ${ }^{11,33}$ In our study, only 6 patients were in the active phase of labor (dilation $>4 \mathrm{~cm}$ to full dilation of cervix) and 10 patients were in phase II of labor at the time of cesarean section. Therefore, due to the low numbers, we did not use these variables in the statistical analysis of the subgroups of maternal age.

There are conflicting reports in the literature regarding the impact of gestational age on niche formation. In our study, no relationship was found between gestational age at the time of delivery and the prevalence and parameters of the niche. This finding is supported by other studies. ${ }^{29,30,32}$ On the other hand, Vikhareva and Valentin found that delivery before 37 weeks gestation was a predictor of large niches. ${ }^{33}$ The study by Hayakawa et al. demonstrated a positive link between the gestational age of 37-41 weeks at delivery and the presence of wedge niches. ${ }^{34}$

The influence of medical conditions associated with pregnancy on uterine niche development was analyzed. No correlation was found between GDM and the prevalence and parameters of niches. However, Antila-Långsjö et al. found GDM and higher body mass index (BMI) to be positively correlated with the incidence of uterine niche after cesarean section. ${ }^{11}$ Interestingly, such a correlation has not been found for pregestational diabetes. In our study, the mean prepregnancy BMI in women diagnosed with cesarean scar niche was $27.1( \pm 6.1) \mathrm{kg} / \mathrm{m}^{2}$ compared to 25.1 $( \pm 5.3) \mathrm{kg} / \mathrm{m}^{2}$ in women without a niche. Consequently, 
it means that most of the women in this study were overweight. In other studies, no correlation was found between BMI and the presence of a uterine niche. ${ }^{33,34}$

Our study also evaluated the influence of gestational hypertension on uterine healing. No statistically significant correlation was found between the frequency of occurrence or parameters of a niche and the presence of gestational hypertension. To our knowledge, only 1 other study evaluated the effect gestational hypertension has on the incidence of uterine scar defect - and failed to show any correlation. ${ }^{35}$ Considering the influence of pregnancy-related systemic diseases, it is impossible to ignore the influence of hypothyroidism on tissue metabolism. The correlation between hypothyroidism and a higher risk of perioperative complications has been known for a long time. ${ }^{36}$ To date, no other studies have been performed to assess the effect of hypothyroidism on uterine healing after cesarean section. In our study, no relationship was found between hypothyroidism and uterine scar niche parameters. When assessing the impact of individual diseases on uterus healing and comparing conflicting reports in the literature, it should be remembered that each population has its own individual characteristics and the incidences of GDM, gestational hypertension and hypothyroidism vary worldwide.

In our study, the effect cervical colonization by microorganisms has on the prevalence and parameters of a uterine niche was evaluated, because previous studies have correlated the bacterial load of the cervix with the bacterial load within the uterine cavity. ${ }^{37,38}$ This suggests that cervical microbiota may be a source of microbes for colonization of the uterine cavity and may influence the healing process of the cesarean section scar. However, our study showed no correlation between the cervical colonization and the prevalence and parameters of uterine niches after cesarean section. This may be due to the use of perioperative antibiotics for surgical prophylaxis. Although, further research is needed to confirm this hypothesis.

In other studies, the influence of inflammatory processes such as postpartum fever, ${ }^{33,35}$ the application of antibiotics during childbirth, ${ }^{39}$ perinatal and puerperal infection in the form of chorioamnionitis, postoperative wound infection, urinary tract infection, and endometritis ${ }^{34}$ were analyzed, but no correlation between the abovementioned variables and the prevalence of niches after cesarean section was found.

\section{Limitations}

The main limitation of our study is the lack of comparison between a single-layer continuous uterine suture and a double-layer uterine suture closure, due to the singlelayer continuous uterine suture being the standard of care at our Department. The other limitation is that we were checking the colonization of the cervical canal without uterine cavity colonization.
The etiology of a uterine niche after cesarean section is multifactorial. In our study, we evaluated a few potential factors that could disturb the proper healing process of the uterus. The effect of other important individual risk factors such as BMI, corticosteroid use, previous myomectomy and smoking status on the prevalence and parameters of cesarean section niche was not investigated in our study, which is a limitation.

\section{Conclusions}

Two- and three-dimensional ultrasonographic cesarean scar assessment revealed that the selected risk factors concerning systemic diseases during pregnancy, maternal medical history and colonization of the cervical canal have no impact on uterine scar healing in women with single-layer uterine closure covering the entire thickness of the myometrium, excluding the decidua.

\section{ORCID iDs}

Joanna Budny-Wińska (D) https://orcid.org/0000-0002-3094-2213 Aleksandra Zimmer-Stelmach (i) https://orcid.org/0000-0003-1114-6980 Michał Pomorski (D) https://orcid.org/0000-0002-4501-353X

\section{References}

1. Anna V, van der Ploeg HP, Cheung NW, Huxley RR, Bauman AE. Sociodemographic correlates of the increasing trend in prevalence of gestational diabetes mellitus in a large population of women between 1995 and 2005. Diabetes Care. 2008;31(12):2288-2293. doi:10.2337/dc08-1038

2. Guariguata L, Linnenkamp U, Beagley J, Whiting DR, Cho NH. Global estimates of the prevalence of hyperglycaemia in pregnancy. Diabetes Res Clin Pract. 2014;103(2):176-185. doi:10.1016/j.diabres.2013.11.003

3. Johnson JA, Tough S; SOGC GENETICS COMMITTEE. Delayed childbearing. J Obstet Gynaecol Can. 2012;34(1):80-93. doi:10.1016/S17012163(16)35138-6

4. Rendtorff R, Hinkson L, Kiver V, Dröge LA, Henrich W. Pregnancies in women aged 45 years and older: A 10-year retrospective analysis in Berlin. Geburtshilfe Frauenheilkd. 2017;77(3):268-275. doi:10.1055/ s-0043-100105

5. Betran AP, Torloni MR, Zhang J, et al. What is the optimal rate of caesarean section at population level? A systematic review of ecologic studies. Reprod Health. 2015;12:57. doi:10.1186/s12978-015-0043-6

6. Pomorski M, Fuchs T, Zimmer M. Prediction of uterine dehiscence using ultrasonographic parameters of cesarean section scar in the nonpregnant uterus: A prospective observational study. BMCPregnancy Childbirth. 2014;14:365. doi:10.1186/s12884-014-0365-3

7. Ludwin A, Martins WP, Ludwin I. Evaluation of uterine niche by threedimensional sonohysterography and volumetric quantification: Techniques and scoring classification system. Ultrasound Obstet Gynecol. 2019;53(1):139-143. doi:10.1002/uog.19181

8. Setubal A, Alves J, Osório F, et al. Treatment for uterine isthmocele, a pouchlike defect at the site of a cesarean section scar. JMinim Invasive Gynecol. 2018;25(1):38-46. doi:10.1016/j.jmig.2017.09.022

9. Jordans IPM, de Leeuw RA, Stegwee SI, et al. Sonographic examination of uterine niche in non-pregnant women: A modified Delphi procedure. Ultrasound Obstet Gynecol. 2019;53(1):107-115. doi:10.1002/ uog.19049

10. van der Voet LF, Bij de Vaate AM, Veersema S, Brölmann HA, Huirne JA. Long-term complications of caesarean section: The niche in the scar. A prospective cohort study on niche prevalence and its relation to abnormal uterine bleeding. BJOG. 2014;121(2):236-244. doi:10.1111/ 1471-0528.12542

11. Antila-Långsjö RM, Mäenpää JU, Huhtala HS, Tomás El, Staff SM. Cesarean scar defect: A prospective study on risk factors. Am JObstet Gynecol. 2018;219(5):458.e1-458.e8. doi:10.1016/j.ajog.2018.09.004 
12. Vikhareva O, Rickle GS, Lavesson T, Nedopekina E, Brandell K, Salvesen KÅ. Hysterotomy level at Cesarean section and occurrence of large scar defects: A randomized single-blind trial. Ultrasound Obstet Gynecol. 2019;53(4):438-442. doi:10.1002/uog.20184

13. Bij de Vaate AJ, van der Voet LF, Naji O, et al. Prevalence, potential risk factors for development and symptoms related to the presence of uterine niches following Cesarean section: Systematic review. Ultrasound Obstet Gynecol. 2014;43(4):372-382. doi:10.1002/uog.13199

14. Vikhareva Osser $O$, Valentin L. Clinical importance of appearance of cesarean hysterotomy scar at transvaginal ultrasonography in nonpregnant women. Obstet Gynecol. 2011;117(3):525-532. doi:10.1097/ AOG.0b013e318209abf0

15. Kaelin Agten A, Cali G, Monteagudo A, Oviedo J, Ramos J, TimorTritsch I. The clinical outcome of cesarean scar pregnancies implanted "on the scar" versus "in the niche". Am J Obstet Gynecol. 2017; 216(5):510.e1-510.e6. doi:10.1016/j.ajog.2017.01.019

16. Vervoort A, Vissers J, Hehenkamp W, Brölmann H, Huirne J. The effect of laparoscopic resection of large niches in the uterine caesarean scar on symptoms, ultrasound findings and quality of life: A prospective cohort study. BJOG. 2018;125(3):317-325. doi:10.1111/1471-0528.14822

17. Pomorski M, Fuchs T, Rosner-Tenerowicz A, Zimmer M. Sonographic evaluation of surgical repair of uterine cesarean scar defects. J Clin Ultrasound. 2017:45(8):455-460. doi:10.1002/jcu.22449

18. Tower AM, Frishman GN. Cesarean scar defects: An underrecognized cause of abnormal uterine bleeding and other gynecologic complications. J Minim Invasive Gynecol. 2013;20(5):562-572. doi:10.1016/j. jmig.2013.03.008

19. Patounakis G, Ozcan MC, Chason RJ, et al. Impact of a prior cesarean delivery on embryo transfer: A prospective study. Fertil Steril. 2016;106(2):311-316. doi:10.1016/j.fertnstert.2016.03.045

20. Budny-Winska J, Zimmer-Stelmach A, Pomorski M. Two- and threedimensional transvaginal ultrasound in assessment of the impact of selected obstetric risk factors on cesarean scar niche formation: The case-controlled study. Ginekol Pol. 2021;92(5):378-382. doi:10. 5603/GP.a2021.0024

21. Osser OV, Jokubkiene L, Valentin L. High prevalence of defects in Cesarean section scars at transvaginal ultrasound examination. Ultrasound Obstet Gynecol. 2009;34(1):90-97. doi:10.1002/uog.6395

22. Bij de Vaate AJ, Brölmann HA, van der Voet LF, van der Slikke JW, Veersema S, Huirne JA. Ultrasound evaluation of the Cesarean scar: Relation between a niche and postmenstrual spotting. Ultrasound Obstet Gynecol. 2011;37(1):93-99. doi:10.1002/uog.8864

23. Armstrong V, Hansen WF, Van Voorhis BJ, Syrop CH. Detection of cesarean scars by transvaginal ultrasound. Obstet Gynecol. 2003; 101(1):61-65. doi:10.1016/s0029-7844(02)02450-x

24. Chen HY, Chen SJ, Hsieh FJ. Observation of cesarean section scar by transvaginal ultrasonography. Ultrasound Med Biol. 1990;16(5): 443-447. doi:10.1016/0301-5629(90)90166-a

25. van der Voet LF, Jordans IPM, Brölmann HAM, Veersema S, Huirne JAF. Changes in the uterine scar during the first year after a caesarean section: A prospective longitudinal study. Gynecol Obstet Invest. 2018;83(2):164-170. doi:10.1159/000478046
26. Pomorski M, Fuchs T, Budny-Winska J, Zimmer A, Zimmer M. Natural history of caesarean scar pregnancy. Ginekol Pol. 2019;90(6):351-352. doi:10.5603/GP.a2019.0054

27. Di Spiezio Sardo A, Saccone G, McCurdy R, Bujold E, Bifulco G, Berghella V. Risk of Cesarean scar defect following single- vs doublelayer uterine closure: Systematic review and meta-analysis of randomized controlled trials. Ultrasound Obstet Gynecol. 2017;50(5):578-583. doi:10.1002/uog.17401

28. Roberge S, Demers S, Berghella V, Chaillet N, Moore L, Bujold E. Impact of single- vs double-layer closure on adverse outcomes and uterine scar defect: A systematic review and metaanalysis. Am J Obstet Gynecol. 2014;211(5):453-460. doi:10.1016/j.ajog.2014.06.014

29. Ofili-Yebovi D, Ben-Nagi J, Sawyer E, et al. Deficient lower-segment Cesarean section scars: Prevalence and risk factors. Ultrasound Obstet Gynecol. 2008;31(1):72-77. doi:10.1002/uog.5200

30. Pomorski M, Fuchs T, Rosner-Tenerowicz A, Zimmer M. Morphology of the cesarean section scar in the non-pregnant uterus after one elective cesarean section. Ginekol Pol. 2017;88(4):174-179. doi:10.5603/ GP.a2017.0034

31. Pomorski M, Fuchs T, Rosner-Tenerowicz A, Zimmer M. Standardized ultrasonographic approach for the assessment of risk factors of incomplete healing of the cesarean section scar in the uterus. Eur J Obstet Gynecol Reprod Biol. 2016;205:141-145. doi:10.1016/j. ejogrb.2016.08.032

32. Yazicioglu F, Gökdogan A, Kelekci S, Aygün M, Savan K. Incomplete healing of the uterine incision after caesarean section: Is it preventable? Eur J Obstet Gynecol Reprod Biol. 2006;124(1):32-36. doi:10.1016/j. ejogrb.2005.03.023

33. Vikhareva Osser O, Valentin L. Risk factors for incomplete healing of the uterine incision after caesarean section. BJOG. 2010;117(9):1119-1126. doi:10.1111/j.1471-0528.2010.02631.x

34. Hayakawa H, Itakura A, Mitsui T, et al. Methods for myometrium closure and other factors impacting effects on cesarean section scars of the uterine segment detected by the ultrasonography. Acta Obstet Gynecol Scand. 2006;85(4):429-434. doi:10.1080/00016340500430436

35. Pan $\mathrm{H}$, Zeng $\mathrm{M}, \mathrm{XuT}$, et al. The prevalence and risk predictors of cesarean scar defect at 6 weeks postpartum in Shanghai, China: A prospective cohort study. Acta Obstet Gynecol Scand. 2019;98(4):413-422. doi:10.1111/aogs.13505

36. Chen HY, Chen SJ, Hsieh FJ. Observation of cesarean section scar by transvaginal ultrasonography. Ultrasound Med Biol. 1990;16(5):443-447. doi:10.1016/0301-5629(90)90166-a

37. Chen $C$, Song $X$, Wei W, et al. The microbiota continuum along the female reproductive tract and its relation to uterine-related diseases. Nat Commun. 2017:8(1):875. doi:10.1038/s41467-017-00901-0

38. Winters AD, Romero R, Gervasi MT, et al. Does the endometrial cavity have a molecular microbial signature? Sci Rep. 2019;9(1):9905. doi:10.1038/s41598-019-46173-0

39. Voet LLFV, Vaate AMJB, Heymans MW, Brölmann HAM, Veersema S, Huirne JAF. Prognostic factors for niche development in the uterine caesarean section scar. Eur JObstet Gynecol Reprod Biol. 2017;213:31-32. doi:10.1016/j.ejogrb.2017.03.039 